\title{
AS FORMAS ASSOCIATIVAS E DE COOPERAÇÃO NO PERCURSO DA AGRICULTURA FAMILIAR DA REGIÃO UVA E VINHO DO RIO GRANDE DO SUL, BRASIL
}

\author{
Associative and cooperation forms in the path of family agriculture in the grape and \\ wine region of Rio Grande do Sul, Brazil
}

\author{
Julice Salvagni* \\ Matheus Johansson** \\ Sofia Cunha*** \\ * Professora Adjunto do Departamento de Ciências Administrativas da UFRGS \\ - julicesalvagni@gmail.com \\ ** Universidade Federal do Rio Grande do Sul (UFRGS) \\ - falecommj@hotmail.com \\ *** Universidade Federal do Rio Grande do Sul \\ - sofiagcunha@gmail.com
}

Recebido em 15/12/2020. Aceito para publicação em 05/07/2021.

Versão online publicada em 09/08/2021 (http://seer.ufrgs.br/paraonde)

Como citar este artigo: SALVAGNI, J. JOHANSSON, M. CUNHA, S. As formas associativas e de cooperação no percurso da agricultura familiar da regoião uva e vinho do Rio Grande do Sul, Brasil.

Para Onde!?, v. 15, n. 1, p. 77-95, 2021.

\begin{abstract}
Resumo:
Aborda-se o Sistema Familiar de produção em relação às cooperativas e associações da Região Uva e Vinho. Os descendentes italianos, sob uma herança cultural, mantiveram as formas associativas historicamente vinculadas ao ciclo de produção. Objetivou-se analisar as relações entre os pequenos produtores e os tipos de cooperações existentes no território, contemplando a identificação do início da agricultura familiar no Brasil, o desenvolvimento da vitivinicultura familiar e a consolidação das cooperativas e associações de trabalho inseridas no âmbito rural. Analisa-se dados das vinícolas familiares e suas características, indicadores geográficos, a história das cooperativas e associações, os eventos e premiações oriundos do desenvolvimento do turismo da região e os números de importação, exportação e comércio do Vinho no Brasil e no exterior. Considera-se que as relações entre as cooperativas e os cooperados divergem em seus objetivos e ideais. Há no agricultor familiar a necessidade de difundir as formas de cooperação para obter melhores condições de trabalho e para disputar as premiações que aferem 0 reconhecimento dos produtos. O nível dos laços vinculantes da região só se mantém sólidos graças a um histórico processo de amadurecimento das diferentes formas de cooperação.
\end{abstract}

Palavras-chave: Agricultura Familiar. Cooperação. Associações. Região Uva e Vinho. Desenvolvimento Rural.

\footnotetext{
Abstract:

The Family Production System is approached in relation to the cooperatives and associations of the Grape and Wine Region. The Italian families, under a cultural heritage, maintained the associative forms historically linked to the production cycle. The objective was to analyze the relationships between small producers and the types of cooperation existing in the territory, including the identification of the beginning of family farming in Brazil, the development of family winemaking and the consolidation of cooperatives and labor associations within the rural context. The data of the family
} 
wineries and their characteristics, geographic indicators, the history of the cooperatives and associations, the events and awards from the tourism development of the region and the numbers of import, export and trade of Wine in Brazil and abroad are analyzed. It is considered that the relations between cooperatives and cooperatives differ in their objectives and ideals. There is a need in the small farmer to spread the forms of cooperation to obtain better working conditions and to compete for awards recognizing products. The level of binding ties in the region remains only solid thanks to a historic process of maturing different forms of cooperation.

Key-words: Family Agriculture. Cooperation. Associations. Grape and Wine Region. Rural Development.

\section{Introdução}

A agricultura familiar não se caracteriza somente por denominações técnicas que contextualizam o tamanho de suas propriedades ou o número máximo de produção dos produtos que cada propriedade escolhe cultivar. Todo o processo histórico que as acompanha resultou na observação de sua cultura, como a reprodução de técnicas e tipos de cultivo, presente nas propriedades, e no modo de como a união desse sistema acarreta na identificação de todo um território.

No Brasil, a agricultura familiar representa $77 \%$ dos estabelecimentos agropecuários do país, nos quais trabalham mais de 10 milhões de pessoas (IBGE, 2017). Conforme revela o censo agropecuário de 2017, o valor da produção destas propriedades supera os 100 bilhões de reais, ainda que signifique apenas $23 \%$ do total produzido em solo brasileiro. Ou seja, os empreendimentos familiares rurais são capazes de fomentar a indústria nacional, cada qual com uma produção especializada em um tipo de produto, cuja associação garante as condições para competir em um mercado dominado pelo agronegócio.

Os pequenos produtores da Região Uva e Vinho do estado do Rio Grande do Sul relacionam-se com essas características, onde o agricultor se encontra competindo no mesmo mercado que empresas de grande porte, com alta capacidade financeira e reconhecimento mundial. A produção vitivinícola e a gastronomia estão entre os principais atrativos dos 47 municípios que compõem a região (ATUASERRA, 2020), refletindo uma forte identificação dos moradores com a tradição colonial italiana, herança dos imigrantes que lá se instalaram há mais de 100 anos (VALDUGA; DARTORA; BABINSKI, 2007). Sendo assim, a agricultura familiar local apropria-se do selo territorial para comercialização de seus produtos com grandes corporações, que detém um tipo de produção e organização própria.

Neste cenário, são necessárias formas associativas - associações de produtores e cooperativas - para que o cultivo e a comercialização dos produtos dessas pequenas empresas familiares atinjam o desenvolvimento e o crescimento esperado. Assim, esse estudo consiste em analisar o Sistema Familiar no âmbito da produção de Uva e Vinho da Serra Gaúcha e os resultados das cooperações ali criadas, a fim de descrever essa cadeia de produção.

Especificamente no município de Garibaldi, recorte geográfico deste estudo que pertence à região aqui estudada, é visível a organização de associações que trazem resultados positivos para a indústria familiar, como é o caso da AVIGA (Associação de Vinicultores de Garibaldi - RS), que reúne pequenos e médios 
produtores destes produtos no estado. O município possui cerca de 30.689 habitantes (IBGE, 2010) e localiza-se no Nordeste do estado Rio Grande do Sul, tem como base de sua economia a indústria e a agricultura, sendo o turismo um dinamizador de tais atividades. Integrando também a região do Vale dos Vinhedos, o município é reconhecido como a Capital Brasileira do Espumante devido ao pioneirismo e qualidade de seus vinhos e espumantes.

Segundo Valduga, Dartora e Babinski (2007, p. 09), o empreendedorismo é forte na região já "que concentra um grande número de empresas de pequeno, médio e grande porte, tornando o turismo como mais uma oferta, entre outras". Predominam ali empreendimentos rurais administrados pelas próprias famílias (IBGE, 2017), que se reúnem em cooperativas e associações de pequenos produtores. Parte-se do entendimento de cooperativas enquanto "empresas com a especificidade de terem de obedecer a um conjunto de princípios e de agir em consonância com um leque de valores. Uns e outros, conjugando-se com uma noção caracterizadora, constituem, na sua globalidade, a identidade cooperativa" (NAMORADO, 2009, p. 99). Complementarmente, esses empreendimentos são caracterizados por Lima (2009, p.91) como "associações voluntárias de trabalhadores", em que todos "são sócios e participam dos processos decisórios, assim como do resultado do labor coletivo". Nesse sentido, é destacado pelo autor o seu caráter autogestionário, em que os próprios trabalhadores são responsáveis pela produção, pelo controle da atividade laboral e pelo produto em si (LIMA, 2009).

Esta pesquisa contempla análise documental, em jornais, revistas, relatórios, plataformas digitais, assim como documentos históricos da região e da trajetória da agricultura familiar brasileira. A área de estudo contempla a Região Uva e Vinho da Serra do Estado do Rio Grande do Sul, com um enfoque direcionado para uma das unidades de cooperativas e associações de trabalho neste território, a AVIGA (Associação de Vinicultores de Garibaldi - RS).

As vinícolas familiares contam com produtos cuja qualidade é reconhecida em premiações nacionais e internacionais, produzidos com modernas técnicas de vinificação. A união destes pequenos produtores em associações e cooperativas tem como objetivo perpetuar técnicas de cultivo e de organização da indústria familiar, mas - que podemos analisar é se a validade desta união está sendo concretizada agregando os pequenos produtores de vinho ou os fazendo abandonarem esses tipos de organizações.

A agricultura familiar e as grandes cooperativas agrícolas "remetem a uma certa polarização, cuja distinção estaria no fato de uma ser destinada mais para a produção de produtos de consumo local ou para o mercado interno e a outra produziria commodities, sobretudo para exportação" (SCHNEIDER, 2010, p. 108). Ou seja, a cooperativa sugere a possibilidade de uma outra organização do trabalho, que não pareada pelas regras individualistas ou do cumprimento de metas, mas sim pela associação de pequenos produtores e estabelecer uma troca de benefícios e obrigações.

Neste sentido, o presente estudo traz uma construção histórica-descritiva da Região Uva e Vinho, discorrendo conceitualmente acerca da agricultura familiar em relação a produção local. Ainda, faz-se uma análise dos modos de cooperar e a autogestão dos empreendimentos da vitivinicultura. Ao final do texto, apresenta-se um

Para0nde!?, Porto Alegre, v.15, n.1, p.77-95, 2021. http://seer.ufrgs.br/paraonde 
panorama do cooperativismo na Região Uva e Vinho, exemplificando na última seção o caso da AVIGA.

\section{Região Uva e Vinho}

A imigração italiana no Rio Grande do Sul iniciou com o objetivo do Governo Imperial de povoar terras devolutas do planalto meridional do estado, agregada a busca do Império por uma nova mão de obra com o fim da escravidão no Brasil. A intenção em implementar um sistema de agricultura familiar para o cultivo de terras na região coincidiu em atrativos para a população rural europeia que passava por crises de extrema pobreza e fome e que viam na Serra Gaúcha, grandes oportunidades de se estabelecerem e desenvolveram sua produção agrícola (SCHWARCZ; STARLING, 2015).

Durante a reterritorialização da região Sul, no início do século $\mathrm{XXI}$, a forma como as terras foram distribuídas entre os imigrantes influenciou fortemente a cultura associativa na região da Uva e Vinho (SALVAGNI et al, 2020). Como proprietários das novas terras, os camponeses desejavam valorizá-las economicamente e assim garantir a renda familiar a partir da exploração da própria terra (MOREIRA, 1985). Santos (1981) identifica que há, neste modo de vida, uma relação de subordinação ao capital, seja devido à reprodução da singularidade do processo de trabalho do colono, seja na cristalização de seu trabalho imposta pelo capital. As tensões advindas deste cenário somam-se à crescente subordinação do campesinato ao trabalho assalariado e à migração de seus herdeiros ao meio urbano, configurando um cenário favorável ao seu desaparecimento (MOREIRA, 1985; POZENATO; GIRON, 2007).

Em contrapartida, a resistência da população campesina se dá através da reafirmação de sua permanência na região e da característica familiar de suas propriedades em uma "estratégia de reprodução não-subordinada" (SANTOS, 1981, p.115). O cooperativismo emerge, neste contexto, como uma iniciativa dos próprios imigrantes para expandir sua produção e potencializar seus ganhos (GIRON, 1987, 2009), contribuindo consequentemente para garantir melhores condições de vida à sua comunidade (SALVAGNI et al, 2020). De modo complementar, ao provocar uma intensa socialização do conhecimento, o movimento associativista configura um ambiente fértil para a inovação, promovendo e acelerando o desenvolvimento local (SALVAGNI et al, 2020).

Segundo Valduga (2011), em 1885, o vinho já havia se tornado o principal produto econômico dessa região, demandando atenção estatal. Entre 1911 e 1913, foram fundadas 16 cooperativas de vinho na região, e numa segunda fase, entre 1929 e 1964, foram criadas outras 59, entre cooperativas de produção, consumo e crédito (GIRON, 2009). Em 1950, a Região Uva e Vinho assumiu relativa independência, ingressando no modo de produção capitalista por meio da organização solidária e do estabelecimento de redes locais (ATUASERRA, 2019). Assim, nas três primeiras décadas do século XX, a Região Uva e Vinho assumiu protagonismo regional, ancorada nos pressupostos de cooperação e competição (SALVAGNI et al 2016).

Muitas famílias vindas da Itália começaram com pequenas produções de uva em suas propriedades e, aos poucos, foram aumentando suas videiras e 
comercializando seus próprios produtos. Assim, molda-se a vocação da Região Uva e Vinho para a produção vitivinícola, contribuindo para a preservação de suas paisagens naturais e dos traços da cultura, gastronomia e arquitetura colonial italiana (ATUASERRA, 2019).

Essa perspectiva imigratória impulsiona o desenvolvimento da vitivinicultura no estado, que atualmente concentra $78 \%$ das propriedades viticultoras brasileiras (IBGE, 2017). Confirma-se também a evidência do território na produção de vinhos, uma vez que 8 em cada 10 destas propriedades estão na Região Uva e Vinho (IBRAVIN; EMBRAPA, 2015), conforme é apresentado a seguir na Figura 1.

Figura 1 - Área de Viticultura no Rio Grande do Sul

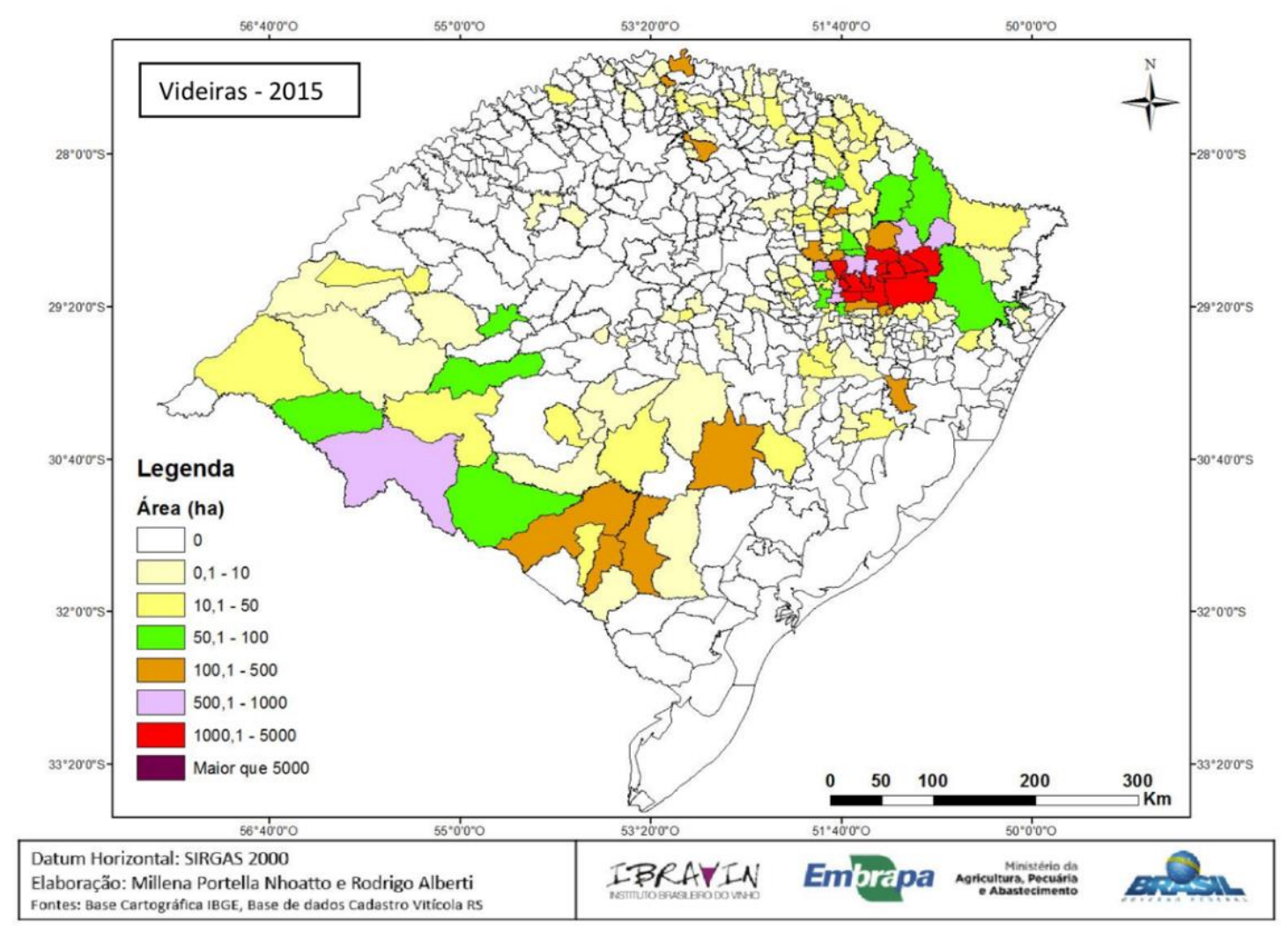

Fonte: Ibravin e Embrapa (2015)

Em uma análise direcionada para a Região Uva e Vinho, observa-se que os municípios com maior quantidade de empreendimentos de viticultura são Caxias do Sul, Flores da Cunha, Farroupilha, Bento Gonçalves e Garibaldi (Tabela 1). Por outro lado, quando considerada a diferença populacional entre as localidades, destaca-se a relevância desse tipo de produção em municípios menores, como Monte Belo do Sul, onde há uma propriedade viticultora a cada 200 habitantes (Gráfico 1). 
Tabela 1 - Número de propriedades viticultoras nos municípios da região Uva e Vinho

\begin{tabular}{|c|c|}
\hline Municípios & Propriedades \\
\hline Caxias do Sul & 1620 \\
\hline Flores da Cunha & 1482 \\
\hline Farroupilha & 1325 \\
\hline Bento Gonçalves & 1306 \\
\hline Garibaldi & 837 \\
\hline Antônio Prado & 709 \\
\hline São Marcos & 623 \\
\hline Monte Belo do Sul & 621 \\
\hline Pinto Bandeira & 484 \\
\hline Nova Pádua & 470 \\
\hline Nova Roma do Sul & 431 \\
\hline Cotiporã & 410 \\
\hline Veranópolis & 296 \\
\hline Ipê & 257 \\
\hline Santa Tereza & 248 \\
\hline Fagundes Varela & 129 \\
\hline Carlos Barbosa & 99 \\
\hline Guaporé & 88 \\
\hline Boa Vista do Sul & 80 \\
\hline Nova Prata & 34 \\
\hline Protásio Alves & 24 \\
\hline Nova Bassano & 23 \\
\hline Vila Flores & 23 \\
\hline Casca & 11 \\
\hline $\begin{array}{c}\text { Santo Antônio do } \\
\text { Palma }\end{array}$ & 11 \\
\hline Vanini & 8 \\
\hline David Canabarro & 4 \\
\hline Muliterno & 3 \\
\hline Vila Maria & 3 \\
\hline Barão & 2 \\
\hline Nova Araçá & 2 \\
\hline Vista Alegre do Prata & 2 \\
\hline Ciríaco & 1 \\
\hline São Domingos do Sul & 1 \\
\hline Camargo & 0 \\
\hline Nova Alvorada & 0 \\
\hline Serafina Corrêa & 0 \\
\hline
\end{tabular}

Fonte: Elaborado pelos autores com base nos dados do Cadastro Vitícola (IBRAVIN; EMBRAPA, 2015) 


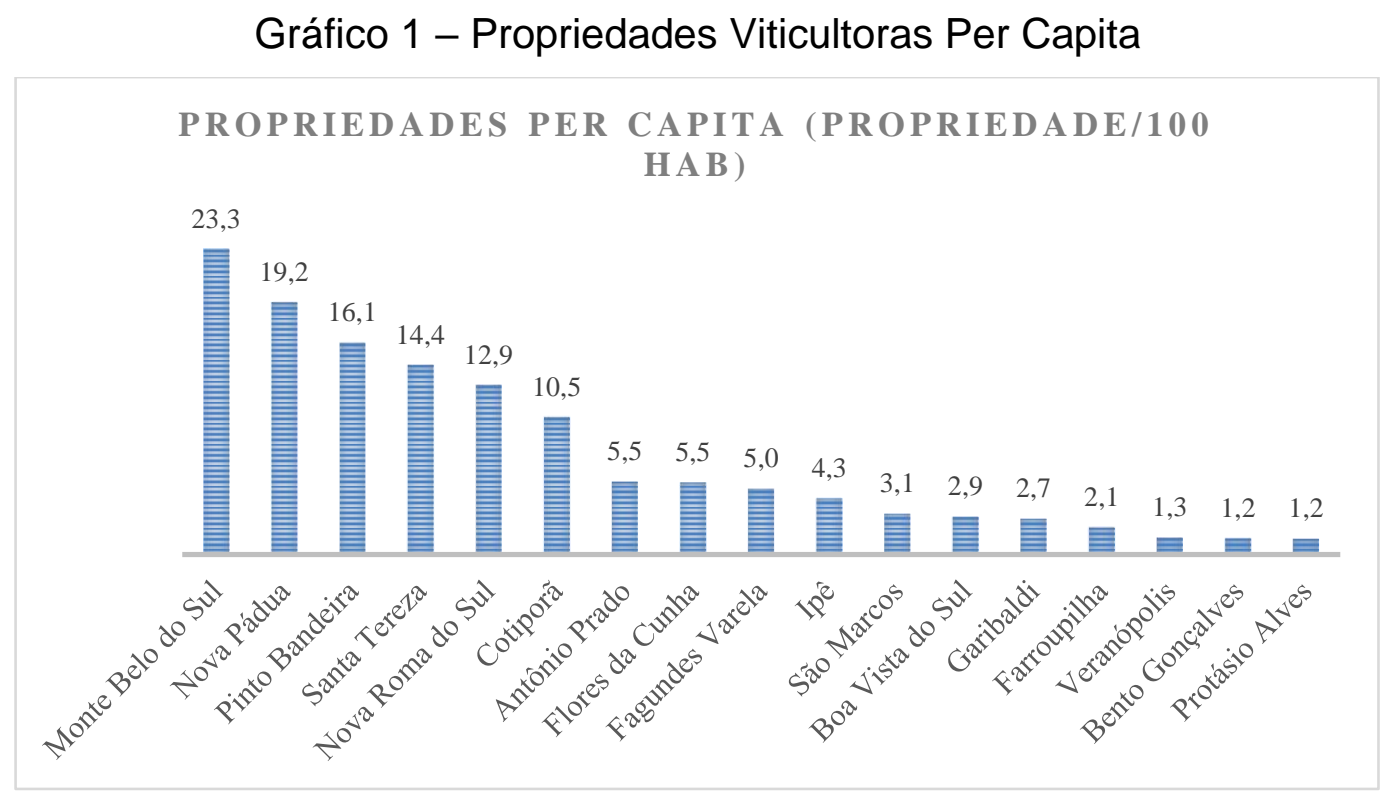

Fonte: Elaborado pelos autores com base nos dados do Cadastro Vitícola (IBRAVIN; EMBRAPA,

2015) e do Censo Agropecuário (IBGE, 2010)

Tal panorama sócio-econômico contribuiu para a certificação do território e reconhecimento da denominação de origem do vinho produzido no Vale dos Vinhedos, caracterizando-o também como um produto com Indicação Geográfica no Brasil (FRIGERI, 2009).

As Indicações Geográficas (IG's) são reconhecidas em países com grande potencial na produção alimentícia e passaram a ser condicionadas às regiões brasileiras com a Promulgação da Lei de Propriedade Industrial LPI/96 (Ministério da Agricultura, Pecuária e Abastecimento). A região do Vale dos Vinhedos foi a primeira a receber essa certificação no ano de 2002, e, desde lá, diversos outros territórios e suas produções e cultivos típicos vieram a serem certificados, como foi o caso das regiões de Pinto Bandeira, Farroupilha, Monte Belo e Altos Montes (INPI). Portanto, é visto que a serra gaúcha pode servir como base para a análise dos resultados obtidos através da aplicação este instrumento nas localidades de produção.

É visto que os consumidores buscam, no contexto de globalização, uma maior clareza dos produtos consumidos e as qualidades particulares atribuíveis as suas localidades geográficas (CHARTERS, SPIELMANN, BABIN, 2017; JOY et al, 2018). Sendo assim, os objetivos da implementação das IG's orbitam em uma ideia de valorização do produto e do produtor (NIEDERLE, 2009; NIEDERLE; VITROLLES, 2010; TONIETTO, 2003; MOLINARI; PADULA, 2013), bem como da preservação do ambiente natural e da cultura local (DONNER et al, 2017; DONNER, 2016).

Niederle e Vitrolles (2010), acerca da vitivinicultura regional, comentam que o produtor está buscando investir em inovações que possibilitem a produção de vinhos de qualidade com custos competitivos. Adicionalmente, Tonietto (2003) ressalta a entrada de vinhos estrangeiros no mercado brasileiro como outro fator que impulsionaria uma nova era na produção da uva e vinho no Brasil, voltada para o ganho de competitividade. 
Os dados do Cadastro Vinícola (IBRAVIN; EMBRAPA, 2015) confirmam essa tendência. Em uma análise histórica do período de 1995-2015, observa-se uma estagnação do número de propriedades viticultoras na Região da Uva e Vinho (Gráfico 2), enquanto a área plantada de vinhedos cresceu 44\% (Gráfico 3). Nesse mesmo período, houve um crescimento exponencial da produção de vinhos em outras regiões do estado, ocasionando um crescimento de $66 \%$ de área plantada no estado como um todo - fenômeno que, entretanto, reduziu a participação da Região Uva e Vinho na produção vitícola estadual de $96 \%$ para $80 \%$.

Gráfico 2 - Propriedades Viticultoras no Rio Grande do Sul

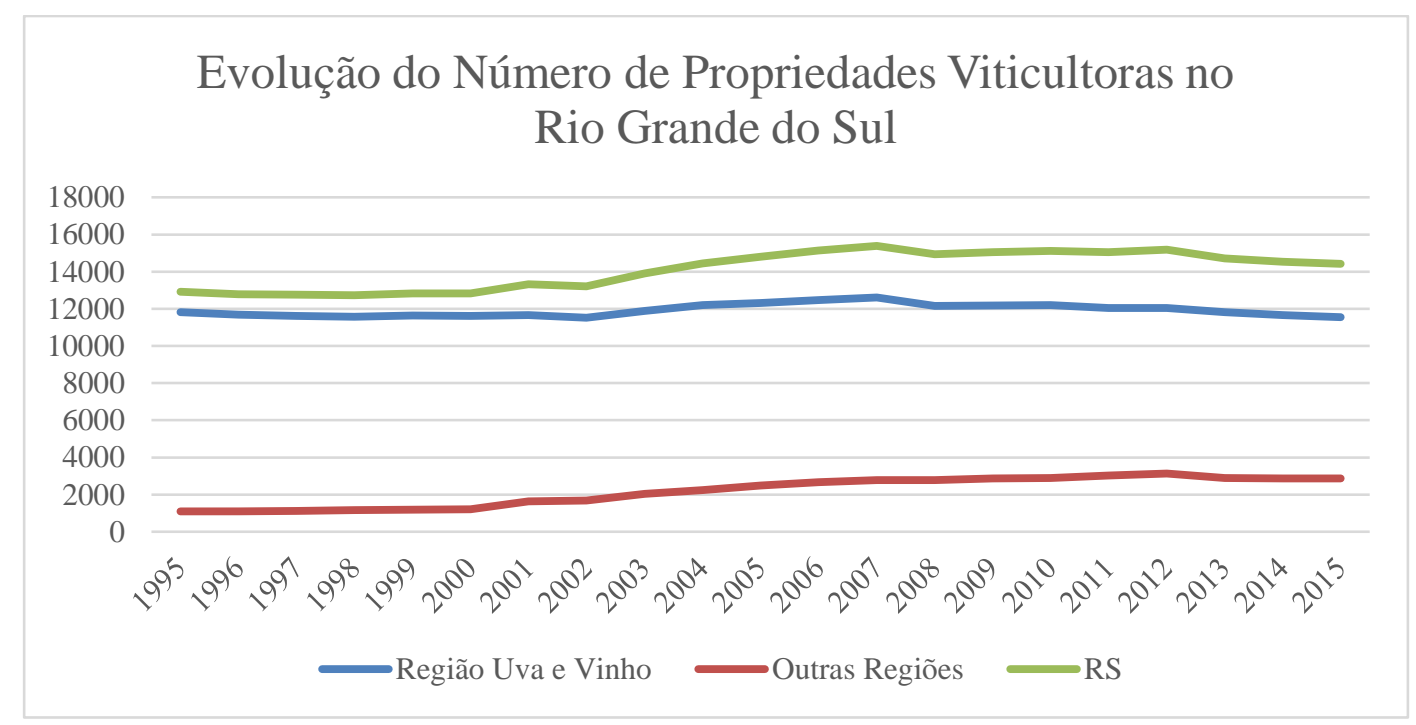

Fonte: Cadastro Vitícola (IBRAVIN; EMBRAPA, 2015)

Gráfico 3 - Área Plantada de Vinhedos no Rio Grande do Sul

Evolução Área Plantada de Vinhedos no Rio Grande do

Sul

50.000

40.000

30.000

20.000

10.000

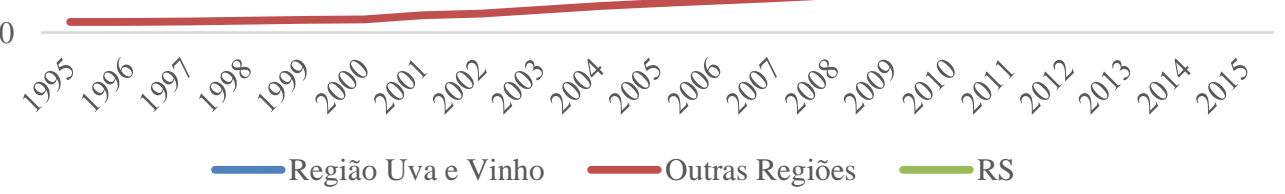

Fonte: Cadastro Vitícola (IBRAVIN; EMBRAPA, 2015) 
Visto isso, é interessante destacar também que, embora $78 \%$ dos estabelecimentos agropecuários com produção de vinho estejam localizados no Rio Grande do Sul, o estado participa com $68 \%$ do vinho produzido e $56 \%$ do vinho vendido no Brasil (IBGE, 2017). Números que reiteram a pequena propriedade da agricultura familiar como base do cultivo regional, como evidencia o gráfico 4.

Gráfico 4 - Participação da Agricultura Familiar na Produção de Uvas

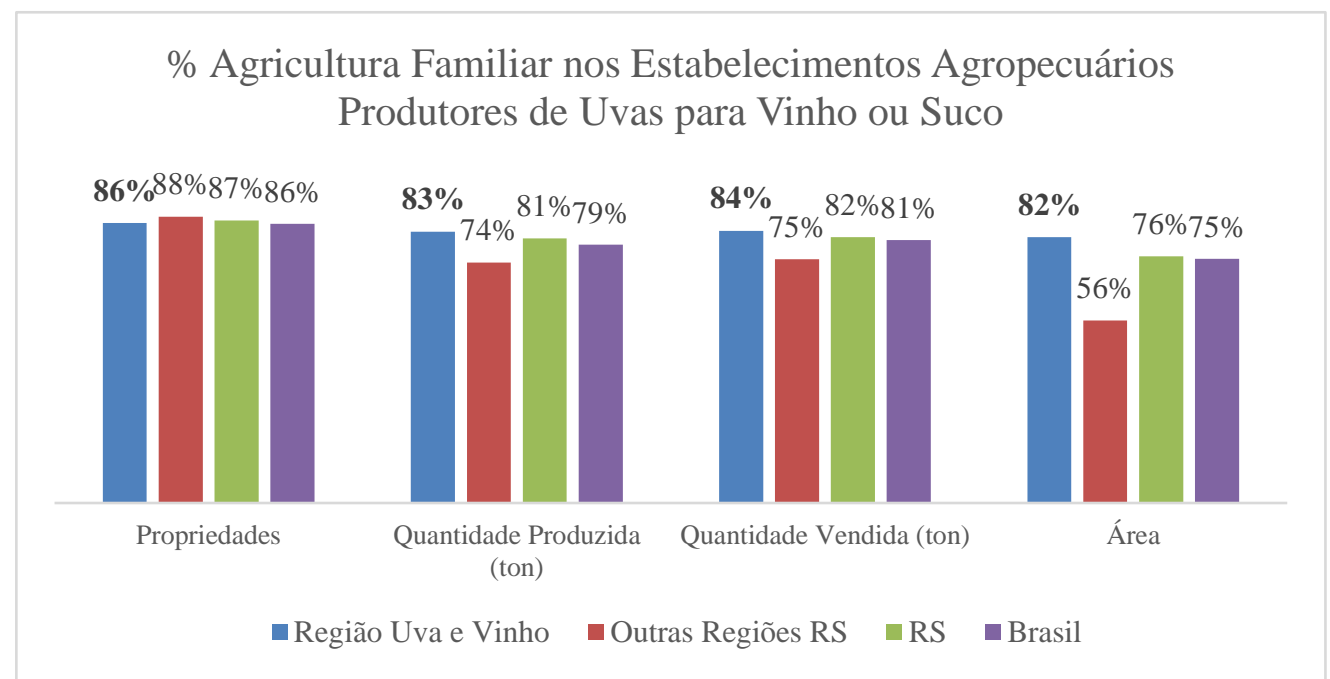

Fonte: Censo Agropecuário (IBGE, 2017)

3. Agricultura familiar: A trajetória dos que não decidem

O debate acerca da reorganização das terras brasileiras começou com a promulgação da Lei 601, em 18 de setembro de 1860, mais conhecida como a Lei de Terras (FONSECA, 2005). Tal princípio tinha como objetivo a legitimação e a regulamentação das terras empossadas ou advindas da divisão por Sesmarias no período Colonial Brasileiro.

Nozoe (2006) enfatiza que a lei provocou significativa mudança em relação a propriedade de terra no Brasil, "ao deixar de integrar o patrimônio pessoal do Imperador, que a distribuía segundo o prestígio social do beneficiário, passava a ser considerada tão somente uma mercadoria, a ser adquirida na proporção do poder econômico de seu comprador" (NOZOE, 2006, p.18). Esse movimento perpetuou uma distribuição desigual de terras, permitindo a venda de antigas áreas empossadas a quem detinha maior poder de compra. O aspecto é central para compreender a transformação do modelo econômico e político visto nesta época de transição onde "todo o projeto de colonização fazia parte de um processo de expansão comercial que era próprio do início do capitalismo" (FONSECA, 2005, p. 3).

Incentivos à colonização das terras devolutas também foram criados, como a oportunidade de vendê-las a colonos estrangeiros, o que se tornou uma saída para os donos de terras substituírem a renda obtida por meio da mão de obra escrava (OLIVEIRA, 2001). Era o início da colonização por imigrantes no país, que trouxeram novos produtos, meios e técnicas de produção que caracterizariam a heterogeneidade do território brasileiro. 
No início da organização de terras no Brasil, "a afirmação da agricultura familiar no cenário social e político brasileiro está relacionada à legitimação que o Estado Ihe emprestou ao criar, em 1996, o Pronaf, Programa Nacional de Fortalecimento da Agricultura Familiar" (SCHNEIDER, 2003, p. 100). O programa financia a implantação, ampliação ou modernização da estrutura de produção no estabelecimento rural, visando à geração de renda e à melhora do uso da mão de obra familiar. Mas, como consequência, o "PRONAF oferece um risco para o sistema bancário e para os agricultores, os critérios de seleção tendem a eliminar os agricultores incapazes de oferecer garantias e contrapartidas" (ABRAMOVAY, 1998).

Schneider (2003) direciona seu estudo à categorização das unidades familiares em unidades capitalistas, como a inserção delas em círculos mercantis. Por essa perspectiva, o debate acerca da implementação do capitalismo nas pequenas propriedades é iminente, uma vez que "a mercantilização crescente das relações de produção" (CONTERATO, SCHNEIDER, 2004, p. 7) pode se conectar às recentes inserções dos produtores familiares em grandes cooperativas da região aqui estudada.

A dinâmica da própria agricultura no espaço rural "vem sendo condicionada e determinada por outras atividades" (SCHNEIDER, 2003, p. 100) onde o produtor inserido no sistema familiar de produção se adapta a mudanças e decisões impostas no espaço territorial. À medida que o tempo decorre, as formas associativas são condicionadas pela adesão das famílias nas vinícolas a outras atividades. Porém, conforme é sinalizado por Santos (2002) é necessário verificar, nesse processo, se "os resíduos do passado são um obstáculo à difusão do novo ou juntos encontram a maneira de permitir ações simultâneas" (2002, p. 25).

É possível identificar tal movimento no processo de Turistificação da Região Uva e Vinho, em que a agricultura familiar da região não acompanha o desenvolvimento acentuado do turismo em relação ao ciclo de tomada de decisões e ao que vem sendo implantado na área (VALDUGA, 2011). O que acontece, nesse caso, é uma adaptação do produtor da agricultura familiar a esse cenário, fazendo uso do turismo como parte de sua renda; fenômeno caracterizado por Schneider (2003) como pluriatividade da agricultura familiar, uma nova mudança estruturada deste sistema. Esse arranjo remete a novas atividades que são desenvolvidas pelos pequenos produtores, dentro ou até mesmo fora de suas propriedades, as quais "podem ser assumidas como objetivo de sustentar ou de dar suporte à unidade doméstica" (SCHNEIDER, 2003, p. 103).

A inclusão do produtor da agricultura familiar no processo de desenvolvimento do turismo e em outras atividades que acontecem na propriedade do trabalhador não advém exclusivamente do Brasil. Na Itália, especificamente em municípios que fazem parte da Sardenha, as cooperativas "foram promovidas pelo estado italiano e mudaram ao longo do tempo de acordo com as maiores tendências econômicas e os modelos de organização" (VARGAS-CETINA et al, 2011, p.127). Assim que foram constatados os benefícios da aderência dos produtores a outras formas de atividade, as cooperativas passaram a incluir seus cooperados na tomada de decisão. Logo, as cooperativas italianas "optaram por retomar ou transformar novos projetos, incluindo atividades como a deleção de uma atração turística local dentro da cooperativa e, quando uma dessas iniciativas falha, a terra retorna a sua função de cultivo" 
(VARGAS-CETINA et al, 2011, p.131).

Paralelamente, é visto que os pequenos produtores de vinho se beneficiam do processo de turistificação da Região Uva e Vinho, obtendo uma renda adicional ao abrir suas propriedades para a visitação de turistas e oferecer a degustação de seus produtos. Entretanto, os agentes envolvidos no processo de turistificação de uma região não incluem os indivíduos do Sistema Familiar de produção no ciclo de tomada de decisões (VALDUGA, 2011). Tais projetos se desenvolvem sem a análise e o estudo das populações e comunidades da região, apesar das mesmas utilizarem o espaço para trabalhar na produção rural e serem suscetíveis, portanto, à influência das políticas econômicas e sociais ali desenhadas.

Estas diretrizes, de ordem política ou legal, exercem diferentes tipos de controle, já que denotam aspectos passíveis de verificação a partir da racionalização do espaço territorial. Sobre esse tópico, Santos (2002, p.184) afirma que "a sociedade local comanda, sobretudo, os aspectos técnicos do trabalho local", nesse caso, a produção de vinho nas propriedades familiares agrícolas com suas técnicas de gestão e cultivo. Para o mesmo autor, "enquanto é residual e incompleto seu comando sobre os aspectos políticos do trabalho local, o controle se dá em outras instâncias" (2002, p.184); como por exemplo, pela não participação dos pequenos agricultores nas decisões da região, validando a ideia de que o que é imposto não é cabível aos verdadeiros agentes do território. Gios e Santuari (2002) complementam essa posição, ressaltando a importância de recuperar o gosto pela participação entre os membros de uma cooperativa: "sem participação, não importa o modelo de organização, o movimento cooperativo não tem futuro" (2002, p.11).

Assim, cabe considerar que políticas de distribuição e regulamentação de territórios, produtos e preços são impostos de maneira errônea sem o devido conhecimento dos quais os principais atores da produção específica possuem. Portanto, falta no senso coletivo o que verdadeiramente retrata um espaço, já que "o espaço deve ser considerado com um conjunto indissociável de que participam, de um lado, certo arranjo de objetos geográficos, objetos naturais e objetos sociais, e, de outro, a vida que os preenche e os anima, seja a sociedade em movimento" (SANTOS, 1998, p.10).

Os descendentes italianos, pelos costumes e pela cultura, passaram de geração em geração o sistema de produção característico de sua propriedade, mantendo a identidade própria no ciclo de produção da uva. No enfoque das técnicas que configuram a historicidade de um território, de acordo com Milton Santos, "a maneira como a unidade entre tempo e espaço vai dando-se, ao longo do tempo, pode ser entendida através da história das técnicas: uma história geral, uma história local" (SANTOS, 2002, p. 29). O autor ainda explica que, com a história das técnicas, é possível "considerar o espaço como fenômeno histórico a geografizar, isto é, a produzir uma geografia como ciência histórica" (2002, p.29). Atualmente, as vinícolas são administradas por descendentes destes produtores que se fixaram no sul do Brasil e que fazem dessa região referência no país e no mundo em produção e comércio de vinhos.

\section{Modos de cooperar e a autogestão dos empreendimentos}


As cooperativas e associações de trabalho refletem as tentativas de união de pequenos produtores por vias de diferentes formas de cooperação existentes em seus territórios para fortalecer sua produção com melhorias nas técnicas utilizadas pelas famílias na produção. Milton Santos explica a relação das possíveis uniões de diferentes técnicas dentro de um espaço, onde "num mesmo pedaço de território, convivem subsistemas técnicos diferentemente datados, isto é, elementos técnicos provenientes de épocas diversas" (SANTOS, 2002, p. 25). Cabe destacar o conceito de técnica para o autor e de como "a relação entre o homem e a natureza, ou melhor, entre o homem e o meio, é dada pela técnica. [Já que] as técnicas são um conjunto de meios instrumentais e sociais, com os quais o homem realiza sua vida, produz e, ao mesmo tempo, cria espaço" (2002, p. 16).

As técnicas na região Uva e Vinho do Rio Grande do Sul não só denominam o tipo de produção, mas também o modo de vida e costumes dos grupos familiares na área. O que se estuda é a aplicação das mudanças que vem condicionando as mais diversas técnicas que hoje existem na região. Para Santos (2002), a regulação da economia e do território impõe-se com mais força à medida que há uma fragmentação técnica e distribuição geográfica do processo produtivo, exigindo uma permanente reunificação. Nesse sentido, a união e a força da coletividade são as formas capazes de aumentar a produtividade e reforçar o reconhecimento dos pequenos produtores e de seus produtos no âmbito local, nacional e internacional, ocasionando a criação de novas formas de associações e cooperações agropecuárias dentro da sociedade vitícola gaúcha.

De acordo com Gimenes e Gimenes (2007, p. 54), o cooperativismo "foi um dos principais responsáveis pelo desenvolvimento do agronegócio nos períodos das décadas de 60 e 70 devido à organização das cadeias produtivas, a difusão da tecnologia e a viabilização da infraestrutura". Segundo os autores, as cooperativas agropecuárias atuam em atividades como assistência técnica, armazenamento, industrialização e comercialização dos produtos, por vezes até fornecendo assistência social. Esses são fatores que também implicam na destinação de recursos do PRONAF a essas mesmas cooperativas agropecuárias, muitas vezes formadas por agricultores do Sistema Familiar, para sua capitalização.

Todo esse apoio dado aos pequenos produtores é fator decisivo para a união deles às cooperativas, mas cabe analisar também a percepção frente às perdas e ganhos que associados de cooperativas e associações agrícolas recebem. Para Bialoskorski Neto (2007), há a necessidade de seguir regras comerciais e respeitar decisões das estruturas de governança que nem sempre são favoráveis aos interesses particulares de um cooperado. Por outro lado, a divergência de princípios e da verdadeira participação dos associados nas decisões da cooperativa é citada por Crúzio (1999) como um fator motivador para mudar as leis cooperativas vigentes e assim "propiciar maior exercício da participação dos associados no processo decisório" (1999, p. 18). O autor ainda remete ao paradoxo existente entre autogestão e a participação do associado nos interesses da cooperativa, uma vez que a autogestão pode excluir ou inibir os interesses dos associados e suas respectivas propostas.

Compactuando com o que Milton Santos analisa ser a verdadeira intenção dos cooperados, percebe-se que "as transferências de técnicas frequentemente aparecem 
como o meio de aumentar a produtividade e a produção e buscar, desse modo, escapar a uma situação de inferioridade" (SANTOS, 2002, p. 146). Contudo, as falsas cooperativas ou as políticas sociais locais podem ir contra o cumprimento de sua função original, chegando até a piorar a condição do trabalhador rural. Ainda assim, muitas cooperativas procuram inserir, efetivamente, os produtos da agricultura familiar em um cenário de concorrência resultante da nova divisão de trabalho. Essas iniciativas produzem, de fato, a "participação no mundo da competitividade, [levando] ao aprofundamento das novas relações técnicas e das novas relações capitalistas. Estas são a base da ampliação do modelo de cooperação e, portanto, da divisão social e territorial do trabalho" (SANTOS, 2002, p. 206).

\section{Um panorama do cooperativismo na Região Uva e Vinho}

As cooperativas e associações estão distribuídas em todo o território nacional, gerando cerca de 372.000 empregos diretos neste sistema. As regiões Sul e Sudeste concentram o maior número de cooperativas, de associados e possuem a maior taxa de participação nas exportações de produtos de cooperativas (OCERGSSESCOOP/RS, 2017).

De acordo com a pesquisa Expressão do Cooperativismo Gaúcho, realizada pelo Sindicato e Organização das Cooperativas do Estado do Rio Grande do Sul (2014 - 2017), há uma forte adesão às ao sistema cooperativista no estado, uma vez que concentra $21 \%$ dos associados do país todo, mesmo reunindo apenas $6 \%$ das cooperativas do Brasil.

O ramo agropecuário é o que concentra a maior participação no cooperativismo no Rio Grande do Sul. Em 2017, as 128 cooperativas agropecuárias gaúchas contavam com 333 mil associados e 36 mil empregados (IBGE, 2017). Dessas, 11 são ligadas à produção vitivinícola, sendo está uma das áreas de atuação agropecuária que menos possui cooperativas no estado. Ainda assim, as cooperativas de vitivinicultura foram responsáveis por $34 \%$ dos produtos embalados comercializados pela cadeia produtiva brasileira da uva e do vinho no ano de 2017 (OCERGS/SESCOOP, 2018)

Em uma análise da indústria de vinhos de Portugal referente à participação e reconhecimento dos produtos, Barros e Santos (2007) compararam a eficiência das cooperativas e das empresas privadas no que tange a busca por reforçar a representação de produtores nacionais no comércio interno - cenário este bastante similar à organização da produção do vinho gaúcho. Em sentido geral, é feita uma demonstração de dados que compactuam com a análise deste estudo sobre a participação da agricultura familiar no processo de produção e comercialização de vinhos no Rio Grande do Sul. Desta forma, em Portugal, "a importância do setor para a economia nacional reflete no fato de $9 \%$ de todas as terras agrícolas serem dedicadas à produção de vinho. [Ou seja], cerca de metade das propriedades são pequenas" (Barros; Santos, 2007, p. 111). Assim como no condado de Trento na Itália, região típica na produção de vinhos, onde "mais de $80 \%$ da agricultura local foi processada e comercializada por uma rede bem desenvolvida de cooperativas e isso gira em torno de pequenas empresas familiares" (GIOS; SANTUARI, 2002, p.3).

Essa característica de fomento às pequenas propriedades locais, assim como

Para0nde!?, Porto Alegre, v.15, n.1, p.77-95, 2021. http://seer.ufrgs.br/paraonde 
na Região Uva e Vinho do Rio Grande do Sul, faz com que a produção do vinho se torne uma alternativa para o incentivo à cooperação das empresas familiares. Neste cenário de associativismo, "o vinho produzido pelas cooperativas é produto dos pequenos fazendeiros-agricultores, que entregam suas uvas à cooperativa para processamento, distribuição e comercialização" (BARROS; SANTOS, 2007, p. 111).

Para exemplificar, destaca-se o caso AVIGA, que é uma organização expressiva da vitivinicultura no município de Garibaldi. A AVIGA (Associação de Vinicultores de Garibaldi) está entre as cooperativas e associações de vitivinicultura na Região Uva e Vinho. Fundada no ano de 1997, a AVIGA surge com o intuito de fortalecer e unir as pequenas indústrias vinícolas de Garibaldi. A criação da associação deu-se no sentido de buscando novas técnicas para o cultivo da uva, informações na elaboração dos vinhos, espumantes e sucos, difusão de cursos de aperfeiçoamento, especialmente para acompanhar a tecnologia avançada em máquinas e equipamentos, além de diversos outros aspectos.

Fundada no ano de 1997, a AVIGA conta com 24 vinícolas associadas, o que a faz ser considerada uma associação com expressividade aos moldes locais. Desde a integração das vinícolas nessa associação, pequenos produtores da agricultura familiar passaram a participar em feiras nacionais e internacionais, aumentando a representatividade do setor junto às instituições públicas e privadas. Ainda, a promoção e participação em feiras e eventos também acaba sendo facilitada pela integração de várias vinícolas, que assim conseguem minimizar os custos e ainda ampliar a divulgação das empresas do setor. Tais encontros e reuniões propiciam uma integração entres as vinícolas, intensificando a troca de conhecimentos e técnicas entre os produtores.

Para prosperar, o ambiente necessita promover o alto potencial que possui, criando um conjunto de condições favoráveis ao desenvolvimento, promover um cenário atrativo e, assim reverter, o êxodo rural observado nos últimos anos no Brasil (ABRAMOVAY, 1998). Uma das principais formas de atender a essa demanda, proporcionando uma possível descentralização urbana no país, é a promoção do ensino rural na agricultura, a qual tem o potencial de aprimorar o desenvolvimento da produção, principalmente dos agricultores do Sistema Familiar que carecem de uma eficiente tecnologia e gestão aplicada ao cultivo e aos conhecimentos técnicos na maioria das vezes. Abramovay (1998) complementa ainda que "o Brasil está entre os países latino-americanos com os piores indicadores em matéria de educação rural e nada indica que este quadro esteja sofrendo uma mudança significativa" (1998, p. 5).

As cooperativas e associações oferecem oportunidades de ensino a esses pequenos produtores quando promovem cursos, oficinas, palestras e formações apoiadas por instituições de ensino. Na região Uva e Vinho, o ensino técnico é promovido em propriedades vinícolas, empresas, cooperativa, associações, universidades e escolas. Além dos eventos organizados pelas prefeituras, as próprias associações e cooperativas dos pequenos produtores de Uva e Vinho realizam congressos e feiras para apresentar seus produtos ou atrair investimento para região.

Uma das cooperativas que integram a AVIGA, a Cooperativa Vinícola Garibaldi, sustenta grandes safras, investimentos e premiações que aferem em um reconhecimento mundial de seus produtos (BRITTO; MAZZARINO; BARDEN, 2016). Criada em 22 de janeiro de 1931, com a reunião de 73 famílias, a cooperativa foi

Para0nde!?, Porto Alegre, v.15, n.1, p.77-95, 2021. http://seer.ufrgs.br/paraonde 
criada a fim de enfrentar, por meio da união associativista, as dificuldades impostas com o fim da crise de 1929 no país. Atualmente, ela conta com 400 famílias associadas e registrou um faturamento anual de $R \$ 155$ milhões em 2018 (COOPERATIVA VINÍCOLA GARIBALDI, 2019). A Cooperativa Garibaldi é destaque nas festividades realizadas na Região Uva e Vinho, as quais visam celebrar os resultados de cada ano e divulgar o desenvolvimento do cultivo e comércio da uva do território.

É reconhecido que a realização de eventos agroindustriais e comerciais faziam parte das atividades comunitárias da comunidade italiana desde os primórdios da chegada dos imigrantes à serra gaúcha (TOMAZZONI; ZANIRATO, 2014; BARBOSA, 2015). A Festa da Uva, realizada em Caxias do Sul, a Fenavinho, de Bento Gonçalves, e a Fenachamp, de Garibaldi, são exemplos da grandiosidade da cultura deste cultivo. Além de promoverem os números de colheitas, shows, feiras e exposições, a realização destes eventos, que acontece de forma autogerida, propaga todo o envolvimento da cultura e da historicidade da sociedade e dos agricultores da região caracterizando toda sua produção e reforçando os vínculos de solidariedade.

\section{Considerações Finais}

Neste estudo, foram analisadas as relações entre os pequenos produtores e os tipos de cooperações existentes no território, contemplando a identificação do início da agricultura familiar no Brasil, o desenvolvimento da vitivinicultura familiar na região e a consolidação das cooperativas e associações de trabalho inseridas no âmbito rural. Foram pesquisados dados secundários sobre as vinícolas familiares e suas características, indicadores geográficos, a história das cooperativas e associações, os eventos e premiações oriundos do desenvolvimento do turismo da região e os números de importação, exportação e comércio do Vinho no Brasil e no exterior.

Considera-se que as relações existentes entre as cooperativas e os cooperados podem, eventualmente, divergir em seus objetivos e ideais, já que as próprias relações tentem a ser naturalmente conflituosas. Contudo, há no agricultor a necessidade de difundir as formas de cooperação não só para obter melhores condições de trabalho, como ainda para disputar as valiosas premiações da área que aferem o reconhecimento dos produtos e assim, participar. As cooperativas de trabalho resultam na melhoria da produção da agricultura familiar e oferecem, muitas vezes, um suporte técnico para o cultivo e gestão das propriedades. Em contrapartida, é observado na região a não aderência dos agricultores a essas formas de cooperação por motivos como medo e divergência de ideias.

Nota-se que a perpetuação dos laços sociais na região ocorre devido a um processo histórico de amadurecimento das diferentes formas de cooperação. Assim, tais possibilidades associativas também ajudam a difundir a ligação do agricultor com - circuito turístico da região, contribuindo para desenvolver outras estratégias relacionadas ao aumento da renda familiar.

Entretanto, há uma tendência de estagnação na comercialização de produtos oriundos da região Uva e Vinho, um movimento que pode estar associado à falta de representatividade dos produtos oriundos da agricultura familiar nos mercados nacionais, se comparado ao grande volume de vinhos importados de outros países.

Para0nde!?, Porto Alegre, v.15, n.1, p.77-95, 2021. http://seer.ufrgs.br/paraonde 
O produto dos pequenos produtores vem sendo substituído por novos entrantes internacionais, dificultando o aumento da representatividade no mercado interno.

Por fim, destaca-se que a agricultura familiar é a base do avanço do cultivo da uva no estado do Rio Grande do Sul e, portanto, o seu fortalecimento está diretamente associado ao desenvolvimento do setor como um todo. Por este viés, ações voltadas para valorizar os pequenos produtores, aumentar a atratividade de sua produção ou fomentar sua participação no sistema cooperativista têm o potencial de alavancar indicadores positivos para o sistema familiar e para o fortalecimento do espaço territorial como um todo.

\section{Referências}

ABRAMOVAY, R. Agricultura familiar e desenvolvimento territorial. Reforma agrária, v. 28, n. 1, p. 2-23, 1998.

ATUASERRA - Associação de Turismo da Serra Nordeste. Histórico da Região Uva e Vinho, 2019. Disponível em < http://www.serragaucha.com>. Acessado em 23/05/2019.

BARBOSA, F. S. Turismo de Eventos na Serra Gaúcha: O Caso da Festa Nacional da Uva de Caxias do Sul, RS/Tourism Events in Serra Gaucha: The Case of Caxias do Sul, RS, National Grape Festival. Rosa Dos Ventos-Turismo e Hospitalidade, v. 7, n. 2, 2015.

BARROS, C. P.; SANTOS, J. C. Comparing the productive efficiency of cooperatives and private enterprises: the Portuguese wine industry as a case study. Journal of rural cooperation, v. 35, n. 886-2016-64577, p. 109, 2007.

BIALOSKORSKI NETO, S. Um ensaio sobre desempenho econômico e participação em cooperativas agropecuárias. Revista de Economia e Sociologia Rural, v. 45, n. 1, p. 119-138, 2007.

BRITTO, J. C.; MAZZARINO, J. M.; BARDEN, J. E. A concepção da estratégia da cooperativa vinícola Garibaldi a partir de valores organizacionais e princípios cooperativos. Revista Estudo \& Debate, v. 23, n. 1, 2016.

CHARTERS, S.; SPIELMANN, N.; BABIN, B. J. The nature and value of terroir products. European Journal of Marketing, [s. I.], v. 51, n. 4, p. 748-771, 2017. Disponível em: <papers://aed090de-45c7-4154-bf93-4909de9194f6/Paper/p462>. Acessado em 20/08/2019.

CONTERATO, M. A.; SCHNEIDER, S. Estratégias de reprodução e mercantilização da agricultura familiar no alto Uruguai/RS: Um estudo de caso no município de três Palmares. XLIII SOBER, Cuiabá, 2004.

CRÚZIO, H. O. Por que as cooperativas agropecuárias e agroindustriais brasileiras estão falindo? Revista de Administração de Empresas, v. 39, n. 2, p. 18-26, 1999.

DONNER, $M$. et al. Place branding, embeddedness and endogenous rural development: Four European cases. Place Branding and Public Diplomacy, [s. I.], v. 13, n. 4, p. 273-292, 2017.

DONNER, M. Understanding place brands as collective and territorial development 
processes. 2016. Montpellier SupAgro, 2016.

FONSECA, R. M. A Lei de Terras e o advento da propriedade moderna no Brasil. Anuario mexicano de historia del derecho, v. 17, p. 97-112, 2005.

FRIGERI, A. F. Os italianos, vinho e turismo: o vale dos vinhedos na serra gaúcha. 2009. Tese de Doutorado, 2009.

GIMENES, R. M. T.; GIMENES, F. M. P. Agronegócio cooperativo: a transição e os desafios da competitividade. Revista Cadernos de Economia, v. 11, n. 20, p. 45-72, 2007.

GIOS, G.; SANTUARI, A. Agricultural cooperatives in the county of Trento (Italy): Economic, organizational and legal perspectives. Journal of Rural Cooperation, v. 30, n. 886-2016-64597, p. 3, 2002.

GIRON, L.S. 80 anos de lutas 1929-2009: a Cooperativa Forqueta e o cooperativismo vitivinícola gaúcho. Porto Alegre, SESCOOP/RS, 132 p. 2009.

GIRON, L. S. "O cooperativismo vinícola gaúcho: a organização inicial”. In: DE BONI, L. A. (org.). A presença italiana no Brasil. Porto Alegre: EST; Fondazione Giovanni Agnelli, 1987.

IBGE - Instituto Brasileiro De Geografia E Estatística. Censo Agropecuário 2017. Disponível em <https://censos.ibge.gov.br/agro/2017>. Acessado em 07/12/2019.

IBGE - Instituto Brasileiro De Geografia E Estatística. Censo Demográfico 2010. Disponível em < https://censo2010.ibge.gov.br>. Acessado em 07/12/2019.

IBRAVIN; EMBRAPA. Cadastro Vitícola do Rio Grande do Sul - 2015. Acessado em $13 / 12 / 2019$

JOY, A. et al. Performance theory and consumer engagement: Wine-tourism experiences in South Africa and India. Research in Consumer Behavior, [s. I.], v. 19, n. October, p. 163-187, 2018.

LIMA, J. C. Cooperativas de Trabalho. IN: CATTANI, Antonio David et al. Dicionário internacional da outra economia. Coimbra: Almedina, v. 345, 2009.

MELLO, L. M. R.; MATTUELA, J. L. Abordagem prospectiva da cadeia produtiva da uva e do vinho do Rio Grande do Sul. Revista de Política Agrícola, v. 8, n. 2, p. 1-19, 1999.

NAMORADO, R. "Cooperativismo". IN: CATTANI, Antonio David et al. Dicionário internacional da outra economia. Coimbra: Almedina, v. 345, 2009.

NIEDERLE, P. A. Controvérsias sobre a noção de indicações geográficas enquanto instrumento de desenvolvimento territorial: a experiência do Vale dos Vinhedos em questão. In: Congresso da Sociedade Brasileira de Economia, Administração e Sociologia Rural. Porto Alegre: UFRGS, 2009.

NIEDERLE, P.; VITROLLES, D. Indicações Geográficas e qualificação no setor vitivinícola brasileiro. Estudos Sociedade e Agricultura, v. 18, n. 1, p. 5-55, 2010.

NOZOE, N. et al. Sesmarias e apossamento de terras no Brasil colônia. Revista Economia, v. 7, n. 3, p. 587-605, 2006.

OCERGS-SESCOOP/RS - Sindicato e Organização das Cooperativas do Estado do 
Rio Grande do Sul. Expressão do Cooperativismo Gaúcho. 2018. Disponível em <http://www.sescooprs.coop.br/app/uploads/2019/01/relatorio-18-seminario-gauchocooperativismo-2018-12-26.pdf>. Acessado em 5/01/2020.

OLIVEIRA, L. L. O Brasil dos imigrantes. Rio de Janeiro: Zahar, 2001.

POZENATO, K. M. M.; GIRON, Loraine Slomp. Identidade: cultura e memória. Métis: História \& Cultura. v.6, n.12, p.137-151, jul-dez, 2007.

MOLINARI, G. T.; PADULA, A. D. A construção social da qualidade na microrregião do Vale dos Vinhedos. Revista de Economia e Sociologia Rural, Piracicaba, v. 51, n. 1, p. 183-202, 2013.

MOREIRA, E. M. Colonos do Vinho. Ensaios FEE, Porto Alegre, v.6, n.2, p. 221-225, 1985.

SALVAGNI, J., VALDUGA, V., NODARI, C.H. Cooperation, innovation and tourism in the grape and wine region, Brazil. Cuadernos de Desarrollo Rural, v. 17, 2020. https://doi.org/10.11144/Javeriana.cdr17.citg

SALVAGNI, J.; VALDUGA, V.; NODARI, C. H. Cooperação como propulsora da inovação em turismo na região Uva e Vinho do Rio Grande do Sul, Brasil. Otra Economía, 2016, 10.19: 253-262.

SANTOS, J. V. T. A reprodução subordinada do campesinato. Ensaios FEE, Porto Alegre, v.2, n. 2, p. 109-117, 1981.

SANTOS, M. Metamorfoses do espaço habitado. São Paulo: Hucitec, v. 4, p. 136, 1988.

A natureza do espaço: técnica e tempo, razão e emoção. Edusp, 2002.

SCHNEIDER, S. Reflexões sobre diversidade e diversificação-agricultura, formas familiares e desenvolvimento rural. RURIS - Revista do Centro de Estudos Rurais. UNICAMP, v. 4, n. 1, 2010.

Teoria social, agricultura familiar e pluriatividade. Revista brasileira de ciências sociais. São Paulo. Vol. 18, n. 51 (fev. 2003), p. 99-122, 2003.

SCHWARCZ, L. M.; STARLING, H. M. Brasil: uma biografia. 1aㅡ ed. São Paulo: Companhia das Letras, 2015.

TOMAZZONI, E. L.; ZANIRATO, S. H. Inovação e identidade vitivinícola da Festa Nacional da Uva de Caxias do Sul (Rio Grande do Sul, Brasil): os cursos de degustação de vinhos como estratégias de Turismo de Experiência. Turismo e Sociedade, v. 7, n. 3, 2014.

TONIETTO, J. Vinhos brasileiros de $4^{\text {a }}$ geração: o Brasil na era das indicações geográficas. Embrapa Uva e Vinho-Comunicado Técnico (INFOTECA-E), 2003.

VALDUGA, V. Raízes do turismo no território do vinho: Bento Gonçalves e Garibaldi - 1870 a 1960 (RS/Brasil). Porto Alegre: UFRGS/PPGGea, 2011.

VALDUGA, V.; DARTORA, J. S.; BABINSKI, L. R. Economia da experiência: vivências na região Uva e Vinho/RS. IV Seminário da Associação Brasileira de Pesquisa e PósGraduação em Turismo, 2007.

VARGAS-CETINA, G.; WOODARD, M.; BESS, E. Corporations, cooperatives, and the 
state: examples from Italy. Current Anthropology, v. 52, n. S3, 2011. 